NBER WORKING PAPER SERIES

\title{
THE MEDICAL CARE COSTS OF YOUTH OBESITY: AN INSTRUMENTAL VARIABLES APPROACH
}

\author{
Adam I. Biener \\ John Cawley \\ Chad Meyerhoefer \\ Working Paper 23682 \\ http://www.nber.org/papers/w23682 \\ NATIONAL BUREAU OF ECONOMIC RESEARCH \\ 1050 Massachusetts Avenue \\ Cambridge, MA 02138 \\ August 2017
}

For their helpful comments and suggestions, we thank Eric Finkelstein, John Mullahy, Nathan Tefft, Nicole Black, John Cullinan and attendees at the Allied Social Science Association meetings, the American Society of Health Economists Biennial Conference and the International Health Economics Association World Congress. Cawley thanks the Robert Wood Johnson Foundation for its support through an Investigator Award in Health Policy Research. The views expressed are those of the authors, and do not necessarily represent those of the Agency for Healthcare Research and Quality, the U.S. Department of Health and Human Services, or the National Bureau of Economic Research.

At least one co-author has disclosed a financial relationship of potential relevance for this research. Further information is available online at http://www.nber.org/papers/w23682.ack

NBER working papers are circulated for discussion and comment purposes. They have not been peer-reviewed or been subject to the review by the NBER Board of Directors that accompanies official NBER publications.

(C) 2017 by Adam I. Biener, John Cawley, and Chad Meyerhoefer. All rights reserved. Short sections of text, not to exceed two paragraphs, may be quoted without explicit permission provided that full credit, including $\odot$ notice, is given to the source. 
The Medical Care Costs of Youth Obesity: An Instrumental Variables Approach Adam I. Biener, John Cawley, and Chad Meyerhoefer NBER Working Paper No. 23682

August 2017

JEL No. D62,I1,I14,I18

\begin{abstract}
This paper is the first to use the method of instrumental variables to estimate the causal impact of youth obesity on U.S. medical care costs. We examine data from the Medical Expenditure Panel Survey for 2001-2013 and instrument for child BMI using the BMI of the child's biological mother. IV estimates indicate that obesity raises annual medical care costs by $\$ 1,354$ (in 2013 dollars) or $159 \%$, which is considerably higher than previous estimates of the association of youth obesity with medical costs; thus, the cost-effectiveness of anti-obesity interventions have likely been underestimated. The costs of youth obesity are borne almost entirely by third party-payers, which is consistent with substantial externalities of youth obesity, which in turn represents an economic rationale for government intervention.

Adam I. Biener

Agency for Healthcare Research and Quality

5600 Fishers Lane

Rockville, MD 20857

adam.biener@ahrq.hhs.gov

John Cawley

2312 MVR Hall

Department of Policy Analysis and Management

and Department of Economics

Cornell University

Ithaca, NY 14853

and NBER

JHC38@ cornell.edu

Chad Meyerhoefer

Rauch Business Center

Lehigh University

621 Taylor Street

Bethlehem, PA 18015

and NBER

chm308@lehigh.edu
\end{abstract}




\section{Introduction}

Over the last several decades, the prevalence of youth obesity in the U.S. has increased significantly. ${ }^{2}$ For example, the prevalence of obesity among youth aged 6-11 years rose from $11.3 \%$ in 1988-94 to $17.4 \%$ in 2011-14 (Ogden et al., 2016). It is well-established that obesity worsens health among adults, but even among youth it raises the likelihood of Type II diabetes, gallbladder disease, sleep apnea, joint problems, and cardiovascular risk factors (Han et al., 2010; Guo and Chumlea, 1999; Dietz and Robinson, 2005; Ogden et al., 2002). The purpose of this paper is to provide the first estimates of the causal effect of youth obesity on medical expenditure in the U.S.

Previous research has estimated the correlation of youth obesity with annual medical costs (John et al., 2012; Trasande and Elbel, 2012; Pelone et al., 2012). For example, Finkelstein and Trogden (2008) found that, on average, obese children and adolescents incur $\$ 220$ more annual medical expenditures than healthy weight children. Monheit et al. (2009) estimated separate models by gender and found that adolescent girls who become obese incur $\$ 790$ more per year in medical expenditures than healthy weight girls; they found no significant increase for boys. These marginal effects represent a roughly $10-40 \%$ increase in average annual medical expenditures for children, which were \$1,914 for children aged 0-17 in 2009 (Berdahl et al., 2013).

Other studies have focused on specific categories of expenditures. Trasande et al. (2009) estimated that childhood obesity was associated with $\$ 237.6$ million in hospitalizations in 2005 , up from \$125.9 million in 2001. Trasande and Chatterjee (2009) estimate that obese children

\footnotetext{
${ }^{2}$ For youth, obesity is defined based on percentile rank in gender-age specific CDC growth charts, which are based on historical distributions of body mass index (BMI), which is calculated as weight in kilograms divided by height in meters squared. A child whose BMI is above the 95th percentile in their respective BMI distribution is classified as obese, and one whose BMI equals or exceeds $120 \%$ of the 95 th percentile is classified as severely obese; see U.S. DHHS (2010); WHO (2000).
} 
aged 6 to 19 years had higher utilization of inpatient and outpatient care, as well as higher prescription drug expenditures.

A limitation of these prior studies is that they estimate the correlation between youth obesity and medical expenditures, not the causal effect. This is because they do not explicitly account for possible endogeneity of weight. For example, poor health may both increase medical expenditures and cause changes in weight, which would bias estimates of the association of weight with medical expenditures. Weight may also be correlated with unobserved socioeconomic status (SES) or access to care, both of which are correlated with medical spending (Freedman et al., 2006). Families with lower SES are more likely to be obese and have higher incidence of poor health or engage in risky behaviors (Fontaine and Bartlett, 2000). However, because many of these families have poor access to care, they may have lower expenditures on medical care, resulting in underestimation of the causal relationship between BMI and medical expenditures. Furthermore, these studies often rely on self-reported or proxy-reported measures of height and weight, and reporting error can bias coefficient estimates (Bound et al., 2001; Cawley, et al., 2015a; Courtemanche et al., 2015).

This paper makes two contributions to the literature. First, provides the first estimates of the causal effect of youth obesity on medical expenditures. Specifically, it addresses the endogeneity of youth weight by estimating IV models using the BMI of biological parents to instrument for their child's BMI. Second, it uses regression calibration to adjust for nonclassical measurement error resulting from misreported height and weight, which eliminates another potential source of bias.

Prior research has used the BMI of biological relatives as instruments to estimate the impact of obesity on labor market outcomes (e.g. Cawley, 2004; Kline and Tobias, 2008). Other 
studies have used these instruments to estimate the impact of adult obesity on medical care. For example, Cawley and Meyerhoefer (2012) instrument for adult BMI using the BMI of biological children and estimate that adult obesity raises annual medical costs by $\$ 2,741$ compared to just $\$ 656$ in models that do not account for endogeneity.

Three recent studies use similar methods to estimate the causal effect of youth obesity on medical care utilization in other countries. Kinge and Morris (2017) study data for England, use the BMI of biological parents as instruments, and estimate that childhood obesity increases doctor visits and medication use. Doherty et al. (2017) use data for Ireland, use the biological mother's BMI as an instrument for youth BMI, and find that obesity raises the number of doctor visits and hospital inpatient stays at age 13 but not at age 9. Black et al. (2017) examine data for Australia, instrument for child BMI using the BMI of biological parents, and estimate that child obesity raises the medical care costs associated with doctor visits and prescription drugs (they do not have data for hospital costs). We complement these studies by producing estimates for the U.S. using data from the Medical Expenditure Panel Survey (MEPS) and by estimating the impact of youth obesity on total medical care costs (including inpatient, outpatient, and prescription drug costs).

We find that the impact of youth obesity on medical expenditures is greater than previously estimated, suggesting that endogeneity of weight and measurement error cause attenuation bias. We also find that the increase in medical expenditures caused by obesity is paid almost entirely by third-party payers instead of out-of-pocket by the child's family members in the household; as a result, youth obesity imposes negative externalities through health insurance.

\section{Empirical Model}




\subsection{Instrumental Variables}

We follow the previous literature (Cawley and Meyerhoefer, 2012; Smith et al., 2009; Trogdon et al., 2008; Kline and Tobias, 2008; Cawley, 2004) and address the endogeneity of weight by using the weight of a biological relative as an instrument. Specifically, we instrument for child BMI using the BMI of the child's biological mother.

The first requirement of an instrument is power - that it strongly predicts the endogenous regressor. Parent BMI is a powerful instrument because roughly half of the variation in weight across individuals is genetic (Comuzzie and Allison, 1998; Grilo and Pogue-Geile, 1991) and each parent contributes roughly half of their child's genes. We test the strength of correlation between parent and child BMI, and find that first-stage F-statistics in our main specifications range from 449 to 1,025 , which far exceed the conventional standard of $F=10$ (Stock et al., 2002).

The second requirement for an instrument is validity - that the instrument affects the outcome only through its correlation with the endogenous covariate, and as a result, is excludable from the second-stage regression. One concern about validity is common household environment; that is, one might be concerned that the instrument (mother's BMI) is affected by a common household environment (related to diet and physical activity) that also affects youth weight. As always, it is impossible to directly test the exclusion restriction, but there is substantial evidence from the behavioral genetics literature that any effect of the common household environment on adult weight is so small as to be undetectable (Nan, 2012;

Silventoinen et al., 2010; Haberstick et al., 2010; Smith et al., 2009; Wardle et al., 2008; Grilo 
and Pogue-Geile, 1991). ${ }^{3}$ That is not to say that environment does not matter for obesity - it clearly does - but what matters is the individual environment (Wardle et al., 2008).

Another potential threat to validity is pleiotropy: the genes that affect BMI may also affect some other characteristic that directly affects medical care costs. The genetics literature has studied whether the single nucleotide polymorphisms (SNPs) that are associated with high BMI are also associated with other characteristics; they find that they are robustly associated with the components of BMI (weight and height), and obesity-related illnesses such as diabetes, high blood pressure, and high cholesterol (which are part of the total effect of obesity), but not characteristics unrelated to obesity that could affect medical care costs (Locke et al., 2015; Speliotes et al., 2010). Thus, findings from the genetics literature tend to be consistent with the identifying assumption although we fully acknowledge that such evidence regarding instrument validity is always suggestive rather than definitive.

\subsection{Misreporting of Height and Weight}

The data we use in this study, the Medical Expenditure Panel Survey (MEPS) asks a single adult in the household to serve as the primary respondent. That person is responsible for reporting not only their own weight and height, but also proxy-reports the weight and height of everyone else in the household, including the children. If proxy-reports are not accurate, then reported child BMI and obesity may not reflect the child's true BMI and weight status. Prior research has documented that adults tend to under-report their own weight and slightly overreport their height, resulting in understated BMI (Cawley et al., 2015a; Shiely et al., 2013; Gorber et al., 2007; Villanueva, 2001). Studies of parental reporting of adolescent BMI show

\footnotetext{
${ }^{3}$ Given research on the effect of obesity on earnings and wages for women (e.g. Cawley, 2004), one might be concerned that maternal weight could affect child weight through the medium of income. However, there is limited evidence of income affecting child weight in developed countries (see the review in Cawley, 2015) and we have reestimated our IV models controlling for household income and found the results to be robust.
} 
slight under-reporting of weight and over-reporting of height that results in under-reports of BMI (Cullinan and Cawley, 2016; Brettschneider et al., 2012; O’Connor and Gugenheim, 2011;

Goodman et al., 2000; Reed and Price, 1998). In their meta-analysis of parental proxy-reporting studies, Lundahl et al. (2014) find that over $50 \%$ of parents underestimate the weight of their overweight and obese children.

Measurement error in child BMI is a potential source of bias not addressed in previous studies of the association of youth obesity with medical expenditures in the U.S. Under certain conditions, IV estimation can correct for bias due to measurement error in the endogenous regressor (Bound et al., 2001). However, IV models are not robust to all forms of measurement error. Correlation between the child's BMI and the proxy reporting error in child BMI (due to under-reporting) combined with positive correlation between parent and child BMI may result in correlation between the IV (parent BMI) and measurement error in child BMI, and a potential upward bias in IV coefficient estimates (O’Neill and Sweetman, 2013).

To assess the potential bias due to under-reporting, we estimated IV models two ways: one in which parent and child BMI were not adjusted for reporting error, and a second in which they were adjusted for such error, using the National Health and Nutrition Examination Survey (NHANES) as validation data. ${ }^{4}$ There is negligible difference in the coefficient estimates across all specifications between uncorrected IV models and those where both child and parent BMI are error corrected, which suggests that measurement error does not significantly bias the IV estimates in this specific context.

\footnotetext{
${ }^{4}$ Error correction is performed by regressing true height and weight on reported height and weight and other observables in the NHANES. The estimated equation is then used to predict true height and weight in the MEPS. We error-correct reported height and weight using the regression calibration method of Courtemanche et al., (2015). See Appendix section A.1 for details of the calibration methods used.
} 
Measurement error may also diminish the explanatory power of the instrument. There are clear advantages to selecting instruments which have superior first-stage performance, as weak instruments can not only lower the precision of IV estimation, but may have considerable finitesample bias (Bound, Jaeger, and Baker, 1995). Even among instruments that are not weak, instruments with higher first-stage F-statistics are preferable as stronger instruments are less sensitive to violations in the exclusion restriction caused by moderate error in the instrument (Small and Rosenbaum, 2008). We find that correcting our instruments for reporting error improves their first-stage performance, so we use that approach throughout our analysis.

\subsection{Model Specification}

Medical spending in general, and on children in particular, is highly positively skewed with a non-trivial number of individuals with zero expenditures, and a small number of individuals with very high expenditures, in any survey year (Monheit et al., 2009; Finkelstein and Trogden, 2008). To account for the shape of the expenditure distribution we use a two-part model of medical expenditures (Jones, 2000). The first part is a Logit model that estimates the probability of having positive medical expenditures (the extensive margin). The second part estimates the amount of medical expenditures conditional on having positive spending (the intensive margin), and is specified as a generalized linear model (GLM) with Gamma variance structure and $\log$ link. ${ }^{5}$ We conduct the specification tests suggested by Manning and Mullahy (2001) to confirm the choice of link function and expenditure distribution. ${ }^{6}$ We also perform a modified Hosmer-Lemeshow test by regressing prediction error from each model on deciles of the distribution of predicted expenditures. We fail to reject the null hypothesis that the decile

\footnotetext{
${ }_{5}^{5}$ As both the Logit and Gamma models are specified as GLMs, we incorporate instrumental variables into both parts of the two-part model using the IV-GLM estimator of Hardin and Carroll (2003).

${ }^{6}$ Park tests confirm our choice of conditional variance; in particular that the variance is proportional to the square of the conditional mean. We find $\lambda=2.03-2.06$ across our samples.
} 
coefficients are jointly equal to zero, indicating the choice of distribution and link function are appropriate.

Weight status for a child is determined by percentile rank in gender-age specific CDC growth charts, which are based on historical BMI distributions prior to the obesity epidemic. A child whose BMI is above the 95th percentile in their respective BMI distribution is classified as obese, and one at or above $120 \%$ of the 95 th percentile is classified as severely obese; U.S. DHHS (2010); WHO (2000). When classifying child weight status, we use child BMI corrected for reporting error in order to avoid misclassification. In all model specifications, we include child age in months and gender (when boys and girls are pooled) to account for the different age and sex specific distributions of BMI.

We measure the impact of obesity as the average marginal effect (AME) of weight gain that moves a child from healthy weight to obese. To estimate the AME, we follow the method of Cawley et al. (2015b). Using estimates from the two-part model of medical expenditures, we predict the level of expenditures associated with the mean BMI among healthy weight children and the mean BMI among obese children. The difference between these two predictions is the AME of moving from healthy weight to obese. To estimate the AME of severe obesity, we analogously subtract the expenditures associated with the mean BMI among healthy weight children from the expenditures associated with the mean BMI among severely obese children. As an extension, we estimate the direct medical costs attributable to youth obesity as the average treatment effect (ATE) of a binary indicator for obesity.

All models are just-identified, using the mother's BMI as the instrument. We use mother's BMI as the instrument because mothers appear in the same household of the child more often than fathers. As a robustness check, we also estimated IV models that also used higher 
orders of mother's BMI (squared and cubed) as instruments and found that the IV estimates of the effects of obesity were relatively unchanged. However, including higher orders of the instrument lowered the first stage F-statistics, so we report results for the just-identified model with higher first-stage power.

Both parts of the two-part model of instrumental variables include the following regressors. Child characteristics include gender, race/ethnicity (White, Black, Hispanic, other race), and child age in months. We also control for whether the child self-reported her height and weight, although less than one percent of children self-reported their BMI when their mother was the primary respondent. The parent characteristics include education level for mothers and fathers if they are present in the household (high school graduate, some college, bachelor's degree or higher, with no high school diploma as the base category). We do not control for parent race because it is highly co-linear with child race. The household characteristics include census region (midwest, south, or west with northeast as the base category), whether the respondent lives in an MSA, household composition (number of household members age 0-5 years, 6-17 years, 18-64 years and over 65), and year fixed effects. We also include two indicator variables for insurance coverage; the first indicates whether the child is covered by public insurance such as Medicaid or CHIP, and the second indicates whether the child is covered through private health insurance. Health insurance variables are potentially endogenous in the model, but we include them because they are important determinants of medical spending. As a robustness check, we re-estimated the models excluding the insurance variables and found similar results.

Costs of youth obesity are likely not entirely borne by the child's family, and costs paid by third party-payers, may represent negative externalities of youth obesity. We extend our 
analysis by estimating the impact of youth obesity on payments made by third-parties as well as out-of-pocket expenditures. Estimates of the impact of youth obesity on third-party payments may obscure important differences in the cost of obesity driven by different insurance coverage. Of particular concern, medical care rendered to children on public health insurance may not be reimbursed at the level private insurance would pay for the same service. As an extension, we estimate models separately by type of insurance coverage: private health insurance or public health insurance (Medicaid or SCHIP) in which we estimate the impact of youth obesity on expenditures paid by insurance.

\section{Data}

The Household Component of the Medical Expenditure Panel Survey (MEPS) is a comprehensive, nationally representative survey of the U.S. civilian non-institutionalized population. In the MEPS, families are surveyed five times during a two-year period about the medical care utilization and expenditures of all members of their household. In addition, information from the household is supplemented by expenditure data collected directly from participants' medical service providers and pharmacies through a Medical Provider Component. For each household, a single individual is the primary respondent; usually the mother. Heights and weights are not measured in the MEPS, and the primary respondent typically reports the heights and weights of everyone in the household. This means that the primary respondent selfreports her weight and height, and proxy-reports the weight and height for everyone else in the household.

We use data from the 2001-2013 MEPS. We limit the sample to children aged 11-17 years in households with their biological mother ${ }^{7}$, where the mother is under 64 years with non-

\footnotetext{
${ }^{7}$ The restricted-use MEPS biological linkage variables identify step-children or extra-familial children who live in the household and are not related to the respondent. However, we cannot distinguish adopted children from
} 
missing BMI. We do not include children younger than 11 years because of high rates of nonresponse for height and weight. We eliminate two children whose mothers had BMI in excess of 80 out of a concern about extreme reporting error. We omit 210 children who were pregnant. We exclude 1,890 children who were underweight, because our focus is on estimating the medical care costs of obesity, and if medical care costs are higher for the underweight because of illness, that could make it more difficult to accurately predict changes in expenditures at high levels of BMI. ${ }^{8}$ We also exclude 54 children with annual medical expenditures in excess of $\$ 50,000$, because such costs are likely due to an extreme health shock rather than obesity. The resulting sample has 36,064 children aged 11-17 years who lived in the same household as their biological mothers.

For each reported medical event, we observe total medical expenditures (from inpatient care, outpatient visits, and prescription drugs), as well as expenditures by payer type (e.g. Medicaid/CHIP, private insurance, out-of-pocket). We omit dental expenditures because it is the only category of medical expenditures that is not verified with providers, and thus is less accurately measured. We inflate all expenditures to 2013 dollars using the All Goods, Urban Consumer Price Index (BLS, 2016).

MEPS data are collected through a stratified multi-stage probability design, which we account for in the calculation of the standard errors for our marginal effects. In particular, we use 128 balanced repeated replications (BRR) and Fay's method to estimate standard errors in our non-IV and IV two-part GLM models. This method accounts for clustering at the PSU-level, stratification, and person weighting.

\section{Results}

biological children. However, adopted children likely represent only about two percent of children (Child Trends, 2012).

${ }^{8}$ Underweight status is determined using error-corrected BMI. 


\subsection{Summary Statistics}

Descriptive statistics are presented in Table 1 for boys and Table 2 for girls. Among boys, $75 \%$ had positive medical expenditures, which averaged \$1,441. Among girls, 78\% had positive medical expenditures, which averaged $\$ 1,411$. Mean error-corrected BMI was 22.6 for both boys and girls. The prevalence of obesity (defined as having a weight-for-height that is at or above the $95^{\text {th }}$ percentile of the historic distribution, with weight and height corrected for maternal proxy reporting error) was $18 \%$ for boys and $15 \%$ for girls. ${ }^{9}$ The prevalence of severe obesity was $4 \%$ for boys and $3 \%$ for girls.

\subsection{Impact of Youth Obesity on Total Medical Expenditures}

Table 3 contains the estimated marginal effects on annual medical expenditures associated with an additional unit of BMI, as well as the marginal effects of moving from healthy weight to obese and moving from healthy weight to severely obese. The first columns are from a two-part non-IV model that does not correct for the endogeneity of child weight, and the second set of columns are from a two-part IV model that does. The first stage F-statistics for the IV models range between and 449 and 1,025.

The IV models indicate that, for boys and girls pooled, an additional unit of BMI raises annual medical care costs by $\$ 103$, obesity raises annual medical care costs by $\$ 1,354$, and extreme obesity raises annual medical care costs by $\$ 2,628$. These are substantially higher than the associations estimated by the non-IV model; for example, whereas the IV model indicates that obesity raises medical care costs by $\$ 1,354$ per year, the non-IV model indicates that obesity is associated with $\$ 310$ higher annual medical care costs. This difference is likely due to omitted variables bias - the various ways in which obese individuals differ from those who are not obese.

\footnotetext{
${ }^{9}$ These are similar to estimates from NHANES of the prevalence of obesity among children aged 2-19 years in the U.S. in 2011-14: 16.9\% for boys and 17.1\% for girls (Ogden et al., 2016).
} 
Subsequent rows of Table 3 present results separately for boys and girls. In general, the estimated impacts of excess weight on medical expenditures are greater for girls than boys. Obesity raises annual medical care costs by $\$ 1,095$ for boys and $\$ 1,687$ for girls, and severe obesity raises annual medical care costs by $\$ 2,149$ for boys and $\$ 3,256$ for girls. However, these differences across sex are not statistically significant.

The marginal effects reported in Table 3 predict the impact of changes in weight near the mean, which can be misleading if the relationship between youth weight and medical expenditures is highly nonlinear. In Figure 1, we use the results of our IV two-part model to illustrate the relationship between predicted medical expenditures and changes in weight status as indicated by the percentile of BMI z-scores from CDC age and sex specific distributions for boys and girls. We use the BMI z-score instead of raw BMI because we are pooling across age, and youth BMI tends to rise with age.

Figure 1 graphs the relationship between BMI z-score and medical expenditures for boys and girls pooled. Medical expenditures are indicated by the solid line, and the dashed lines depict the $95 \%$ confidence intervals. A dotted line shows the distribution of BMI z-scores in our sample. ${ }^{10}$ The most important conclusion from Figure 1 is that medical care costs are very nonlinear in BMI z-score; for the vast majority of the range of BMI medical care costs rise only slightly; however, they rise exponentially for youth with BMI z-scores over the $90^{\text {th }}$ percentile.

Figure 2 graphs the relationship between BMI z-score and medical expenditures separately for boys and girls; for the sake of clarity we omit the lines for the $95 \%$ confidence intervals and the distribution of BMI z-score, but a version with those is available upon request. The graph indicates that the relationship between medical care costs and BMI z-score is similar

\footnotetext{
${ }^{10}$ Note that the z-scores are based on the historic distribution of BMI. Because of the rise in weight over time, more of the sample is at higher z-scores than would be the case if the z-scores were based on the MEPS sample.
} 
for boys and girls. However, boys have slightly higher medical expenditures over the range of lower BMI z-scores. Girls' medical expenditures rise at a higher rate over the range of healthy weight BMI z-scores ( $\mathrm{z}<85^{\text {th }}$ percentile), overtaking boys' medical expenditures just above the $50^{\text {th }}$ percentile and rising at an increasingly higher rate beyond the $50^{\text {th }}$ percentile. Above the obesity threshold of BMI z-score at the $95^{\text {th }}$ percentile, expenditures rise exponentially with BMI for both boys and girls.

All of the estimates presented so far are of the increase in expenditures associated with BMI and obesity. Next, we estimate the total medical care costs associated with different weight classifications (healthy weight, obese, severely obese). Table 4 contains predicted per capita total annual medical expenditures for healthy weight, obese, and severely obese children, as well as directly estimated ratios of predictions across weight classes. For boys and girls pooled, predicted annual expenditures are $\$ 875$ among the healthy weight, $\$ 2,230$ among the obese, and $\$ 3,504$ among the severely obese. Thus, obesity raises medical care costs by $159 \%$ and severe obesity raises them by $310 \%$. These are higher for girls than boys; obesity raises medical care costs by $128 \%$ among boys and $200 \%$ among girls, and extreme obesity raises medical care costs by $252 \%$ among boys and $389 \%$ among girls.

\subsection{Externalities of Youth Obesity}

We extend the above analysis to estimate the impact of youth obesity on expenditures paid by third parties, as well as out-of-pocket. In Table 5, the first set of columns show the impact of weight on expenditures by all third-party payers, and the second set of columns show

the impact of weight on the household's out-of-pocket expenditures. In every case, the impact of weight on out-of-pocket expenditures is small and not statistically significant, even for severe obesity. In contrast, the impact of weight on expenditures by third-party payers is large, and not 
statistically different from the impact on overall expenditures that was shown in Table 3 . In other words, virtually all of the increases in medical expenditures due to youth BMI are external costs, borne by third-party payers rather than the household of the child.

As an extension, we examine the impact of weight on medical expenditures paid by insurance by type of health insurance coverage. Table 6 provides IV results for expenditures paid by insurance among covered by private insurance or public insurance (Medicaid or CHIP). For boys and girls pooled, there are no significant differences across payer type in the impact of weight on medical expenditures, although the impact of weight on insurance payments is slightly larger for children with private coverage. However, when we separate our samples by gender, significant differences in the impact of weight across sources of coverage become apparent. Specifically, obesity is associated with $\$ 630$ higher medical expenditures per year for boys with public health insurance, versus $\$ 1,306$ higher medical expenditures for boys with private insurance. For girls, the difference is in the opposite direction, though less pronounced, with the impact of obesity being $\$ 1,547$ for girls with public health insurance versus $\$ 1,165$ for girls with private coverage. In other words, obesity raises insurance paid medical care costs more for boys with private coverage than boys with public coverage, but the opposite is true for girls. Because of that difference across boys and girls, when boys and girls are pooled the effect of obesity on insurance paid medical costs is not significantly different for those with public and private insurance.

We re-estimate the medical care costs of youth in specific weight classifications, this time focusing just on expenditures by third-party payers and estimated separately by type of insurance coverage; the results are presented in Table 7. Among youth with private health insurance, obesity (relative to healthy weight) raises medical expenditures by the insurance company by 
$153 \%$, and severe obesity raises them by $305 \%$. Among youth with public health insurance, obesity raises medical expenditures by public health insurance by similar percentages: $176 \%$ for obesity and $310 \%$ for severe obesity.

Controlling for type of insurance coverage, there are two notable differences by gender. First, among those with private health insurance, severe obesity is associated with a greater increase in third-party payments among boys (425\%) than girls (292\%). This is because the medical expenditures of the severely obese are greater among boys than girls, while the expenditures of the healthy weight are similar for boys and girls. The second notable gender difference is that, among those with public health insurance, obesity raises public health insurance expenditures by $319 \%$ for girls compared to $103 \%$ for boys, and severe obesity raises them $625 \%$ for girls compared to $171 \%$ for boys. This is due to two factors: obesity and severe obesity are associated with higher costs for girls than boys, and healthy weight is associated with lower costs for girls than boys.

\subsection{Aggregate Expenditures Due to Youth Obesity}

The two-part IV model of medical expenditures can also be used to estimate the aggregate medical costs of youth obesity in the U.S. To do this, we re-estimated our models using a binary indicator of obesity (based on weight and height corrected for reporting error) in place of continuous BMI, and calculated the total direct costs attributable to youth obesity that corresponds to the population of children like our IV sample: aged 11-17 and living in the same households as their biological mothers who are not underweight or pregnant (which is $76 \%$ of all children). Table 8 shows that from 2001 to 2013, the annual direct cost of youth obesity averaged $\$ 9.33$ billion of which $\$ 9.31$ billion ( $99.7 \%$ ) was borne by third party payers. In the most recent year (2013), the total direct cost of youth obesity was $\$ 13.37$ billion. 
Given the nature of the instrument used in the IV model, the sample consists of children in the same household as their biological mothers who are not underweight or pregnant. As a result, our estimates of the direct costs attributable to youth obesity are not those for the full population of children aged 11-17. Under the strong assumption that the estimated effects of obesity in our subpopulation generalize to the full population of children aged 11-17 years, we estimate that the total direct cost of youth obesity from 2001 to 2013 averaged $\$ 12.4$ billion per year. ${ }^{11}$ For the most recent year (2013), it totaled \$17.6 billion, up from \$10.7 in 2001.

\section{Discussion}

This paper provides the first estimates of the effect of youth obesity on medical care costs for the U.S. that are corrected for both for endogeneity and reporting error in weight. We estimate a two-part model of instrumental variables that exploits the heritable component of weight by using the BMI of the biological mother as an instrument for the BMI of the child, and also correct for reporting error in child and adult weight by using external validation data in conjunction with instrumental variables.

We estimate that youth obesity (relative to healthy weight) raises annual medical expenditures by $\$ 1,349$ for boys and girls pooled; when estimated separately by gender the cost of youth obesity is greater for girls $(\$ 1,686)$ than boys $(\$ 1,085)$. Assuming that the results for our sample generalize to the population of youth, the results of the IV model imply that obesity among 11-17 year olds raised annual medical care costs by $\$ 17.5$ billion in 2013 .

\footnotetext{
11 Using the MEPS sampling weights, we calculated that the population of children aged 11-17 from 2001 to 2013 was an average of 29.4 million per year, while the subpopulation of children in the same household as their biological mothers was an average of 22.2 million per year. To generalize our direct cost estimate, we multiply our subpopulation estimate by $29.4 / 22.2$ to inflate it to the full population.
} 
We also estimate that severe obesity (relative to healthy weight) raises annual medical expenditures by $\$ 2,618$ for boys and girls pooled; when estimated separately by gender the increase is greater for girls $(\$ 3,255)$ than boys $(\$ 2,127)$.

Virtually all (99.3\%) of the increase in medical expenditures associated with youth obesity is paid by third-party payers. This implies that youth obesity imposes substantial externalities through the health insurance system. Such externalities represent an economic rationale for government intervention to prevent and reduce childhood obesity (e.g. Cawley, 2015). However, to some extent this externality may simply represent a transfer; i.e. it may not result in deadweight loss to society if youth do not exhibit the moral hazard of gaining weight, or parents do not underinvest in healthy weight for their children, because the costs of youth obesity are borne by third-party payers (Bhattacharya and Sood, 2011; Cawley, 2015).

We find that the impact of weight on medical care costs is highly nonlinear. For most of the range of BMI z-score, medical costs rise only modestly. However, above the $90^{\text {th }}$ percentile, medical costs rise exponentially.

In all cases, the estimates of the IV model are considerably higher than those from the non-IV model, which suggests considerable omitted variable bias in the non-IV models. Our finding that the causal effect of youth obesity on medical care costs is greater than previously appreciated has important implications for policy. Many estimates of the cost-effectiveness of interventions to prevent or reduce youth obesity are based on estimates of the association of youth obesity with medical care costs, which underestimate the causal effect (e.g. Gortmaker et al., 2015; Trasande, 2010; Whitlock et al., 2010; Brown et al., 2007; Wang et al., 2003). For example, Gortmaker et al. (2015) evaluate the cost effectiveness of seven interventions to reduce childhood obesity. Their analysis utilizes the estimate in Finkelstein and Trogden (2008) that 
youth obesity is associated with $\$ 282$ (2014 dollars) higher expenditures, which is far below our estimate of the causal effect of youth obesity on medical expenditures of $\$ 1,354$ (2013 dollars). As a result, studies may be underestimating the cost-effectiveness of interventions that successfully prevent and reduce youth obesity.

As with all IV models, one must be cautious about instrument validity. We assume that the instrument - mother's BMI - is correlated with the endogenous regressor (youth weight) because of the genetic variation in weight and not because of a common household environment effect on the mother's weight. This assumption is supported by extensive research in genetics that finds a strong genetic component to the weights of youth and adults, and a negligible common household environmental effect on adult weight (e.g. Wardle, 2008; Silventoinen et al., 2010). It is also supported by the genetics literature that finds that the SNPs associated with high BMI are generally not associated with characteristics unrelated to high BMI (e.g. Speliotes et al., 2010; Locke et al., 2015). We have also conducted a falsification test in which we used stepparents as an instrument for child weight, and found that it was not a powerful instrument. This is consistent with previous studies (e.g. Cawley and Meyerhoefer, 2012; Au et al., 2017) that conducted falsification tests using unrelated individuals as instruments and found insignificant correlations in weight in the first stage. While one must always be wary because it is impossible to prove the null hypothesis of validity, the available evidence is consistent with validity of the instrument.

There are limitations to our approach. As with any model of instrumental variables, identification relies on an exclusion restriction that is ultimately untestable. Also, the MEPS data only allow us to compare the medical expenditures of youth at different levels of BMI; it does not allow us to observe how medical expenditures change with changes in BMI. Another 
limitation is that BMI is an imperfect measure of fatness (Burkhauser and Cawley, 2008;

O’Neill, 2015). Ideally we would have more accurate measures of fatness such as percent body fat, but BMI is the only measure of obesity available in the MEPS. A further limitation is that we are only able to examine short-run effects of youth obesity; although the MEPS contains data on medical expenditures over a two-year period, we are unable to examine how youth obesity affects adult medical expenditures, or how one's long-term weight history affects current-year medical expenditures. Doherty et al. (2017), however, find that a longer duration of childhood obesity is associated with a larger increase in health care utilization. Weight and height are selfreported or proxy-reported in the MEPS; necessitating that we adjust for reporting error using the NHANES as validation data. We are unable to examine the impact of youth obesity on specific categories of medical expenditures (e.g. inpatient care or prescription drugs) because of the limited sample size. Finally, our identification strategy requires us to estimate models of youth who are living with their biological mothers; as a result, caution should be used when generalizing to the entire youth population. However, an advantage of this study relative to ones that used similar approaches to study adult obesity is that the sample selection necessary for the IV model is less restrictive for children than adults; i.e. a higher percentage of youth live with their biological mother than the percentage of adults who live with a biological child. Thus, these results for childhood obesity may more easily generalize to the population of children than the results for adult obesity to the population of adults.

Despite these limitations, our analysis contributes to the literature on the costs of obesity by providing the first estimates of the impact of youth obesity on US medical expenditures that are corrected for both endogeneity and measurement error. These estimates are considerably higher than associations of youth obesity with medical expenditures, and as a result, effective 
policies and interventions to prevent and reduce youth obesity may be more cost-effective than previously appreciated. 


\section{Works Cited}

Berdahl T. A., B. S. Friedman, M.C. McCormick and L. Simpson. 2013. "Annual Report in Health Care for Children and Youth in the United States: Trends in Racial/Ethnic, Income, and Insurance Disparities over Time, 2002-2009. Academic Pediatrics, 13(3): 191-203

Black, N., R. Hughes, A. Jones, and S. Kassenboehmer. 2017. "The Health Care Costs of Childhood Obesity in Australia." Paper presented at the 2017 IHEA Conference, Boston MA.

Bhattacharya, J. and N. Sood. 2011. "Who Pays for Obesity?" Journal of Economic Perspectives, 25(1): 139-58.

Biro, F. M. and M. Wien. 2010. Childhood Obesity and Adult Morbidities. American Journal of Clinical Nutrition, 91(5):1499S-15005S.

Bound, J., C. Brown, and N. Mathiowetz. 2001. Measurement Error in Survey Data. Handbook of Econometrics, 5:3705-3843.

Bound, J, D A. Jaeger, and R Baker. 1995. "Problems with Instrumental Variables Estimation when the Correlation Between the Instruments and the Endogenous Explanatory Variables is Weak," Journal of the American Statistical Association, 90 (June): 443-450.

Brettschneider, A. K., U. Ellert, and A. Schaffrath Rosario. 2012. Comparison of BMI Derived from Parent-Reported Height and Weight with Measured Values: Results from the German Kiggs Study. International Journal of Environmental Research and Public Health, 9(2):632-647.

Brown, H. S., A. Perez, Y.-P. Li, D. Hoelscher, S. Kelder, and R. Rivera. 2007. The Cost-Effectiveness of a School-Based Overweight Program. International Journal of Behavioral Nutrition and Physical Activity, 4(1):47.

Burkhauser, R. V. and J. Cawley. 2008. Beyond BMI: The Value of More Accurate Measures of Fatness and Obesity in Social Science Research. Journal of Health Economics, 27(2):519-529.

Cawley, J. 2004. The Impact of Obesity on Wages. The Journal of Human Resources, 39(1):451-474.

Cawley, J. 2015. An economy of scales: A Selective Review of Obesity's Economic Causes, Consequences, and Solutions. Journal of Health Economics, 43:244-268.

Cawley, J., J. C. Maclean, M. Hammer, and N. Wintfeld. 2015a. Reporting Error in Weight and its Implications for Bias in Economic Models. Economics \& Human Biology, 19:27-44.

Cawley, J. and C. Meyerhoefer. 2012. The Medical Care Costs of Obesity: An Instrumental Variables Approach. Journal of Health Economics, 31(1):219-230.

Cawley, J., C. Meyerhoefer, A. Biener, M. Hammer, and N. Wintfeld. 2015b. Savings in Medical Expenditures Associated with Reductions in Body Mass Index among US Adults with Obesity, by Diabetes Status. PharmacoEconomics, 33(7):707-722.

Child Trends. 2012. Adopted children. Available at: https://www.childtrends.org/?indicators=adoptedchildren 
Comuzzie, A. G. and D. B. Allison. 1998. The Search for Human Obesity Genes. Science, 280(5368):1374-1377.

Courtemanche, C., J. C. Pinkston, and J. Stewart. 2015. Adjusting body mass for measurement error with invalid validation data. Economics \& Human Biology. 19:275-293

CPI Inflation Calculator. 2017. Bureau of Labor Statistics. Available at https://www.bls.gov/data/inflation_calculator.htm

Cullinan, J. and J. Cawley. 2016. Parental Misclassification of Child Overweight/Obese Status: The Role of Parental Education and Parental Weight Status. Economics \& Human Biology, 24:92-103.

Doherty, E., J. Cullinan, M. Queally, and P. Gillespie. 2017. "The Impact of Childhood Overweight and Obesity on Healthcare Utilisation.” Economics \& Human Biology, 27:84-92.

Dietz, W. H. (1998). Health Consequences of Obesity in Youth: Childhood Predictors of Adult Disease. Pediatrics, 101(518).

Dietz, W. H. and T. N. Robinson. 2005. Overweight Children and Adolescents. The New England Journal of Medicine, 352(1):2100-2109.

Finkelstein, E. A. and J. G. Trogden. 2008. Public Health Interventions for Addressing Childhood Overweight: Analysis of the Business Case. American Journal of Public Health, 93(3):411-415.

Fontaine, K. R. and S. J. Bartlett. 2000. Access and Use of Medical Care among Obese Persons. Obesity Research, 8(5):403-406.

Freedman, D. S., L. K. Khan, M. K. Serdula, C. L. Ogden, and W. H. Dietz. 2006. Racial and Ethnic Differences in Secular Trends for Childhood BMI, Weight, and Height. Obesity, 14(2):301-308.

Goodman, E., B. R. Hinden, and S. Khandelwal. 2000. Accuracy of Teen and Parental Reports of Obesity and Body Mass Index. Pediatrics, 106(1):52-58.

Gorber, S. C., M. Tremblay, D. Moher, and B. Gorber. 2007. A Comparison of Direct vs. Self-Report Measures for Assessing Height, Weight and Body Mass Index: a Systematic Review. Obesity Reviews, 8:307-326.

Gortmaker, S. L., Y. C. Wang, M. W. Long, C. M. Giles, Z. J. Ward, J. L. Barrett, E. L. Kenney, K. R. Sonneville, A. S. Afza, S. C. Resch, and A. L. Cradock. 2015. Three Interventions that Reduce Childhood Obesity are projected to Save More Than They Cost to Implement. Health Affairs, 34(11):1932-1939.

Grilo, C. M. and M. E. Pogue-Geile. 1991. The Nature of Environmental Influences on Weight and Obesity: A Behavior Genetic Analysis. Psychological Bulletin, 110(3):520-537.

Guo, S. S. and W. C. Chumlea. 1999. Tracking of Body Mass Index in Children in Relation to Overweight in Adulthood. The American Journal of Clinical Nutrition, 70(1):145-148.

Haberstick, B., J. Lessem, M. McQueen, J. Boardman, C. Hopfer, A. Smolen, and J. Hewitt. 2010. Stable Genes and Changing Environments: Body Mass Index across Adolescence and Young Adulthood. Behavioral Genetics, 40(4):495-504. 
Han, J. C., D. A. Lawlor, and S. Y. S. Kimm. 2010. Childhood Obesity. Lancet, 375(9727):1737-1748.

Hardin, J. W. and R. J. Carroll. 2003. Measurement Error, GLMs, and Notational Conventions. The Stata Journal, pages 1-12.

John, J., S. B. Wolfenstetter, and C. M. Wenig. 2012. An Economic Perspective on Childhood Obesity: Recent Findings on Cost of Illness and Cost Effectiveness of Interventions. Nutrition, 28(9):829-839.

Jones, A. (2000). Health Econometrics. In Culyer, A. J. and Newhouse, J. P., editors, Handbook of Health Economics, volume 1, chapter 6, pages 265-344. 1 edition.

Keating, C. L., M. L. Moodie, and B. A. Swinburn. 2011. The Health-Related Quality of Life of Overweight and Obese Adolescents - a Study Measuring Body Mass Index and Adolescent-Reported Perceptions. International Journal of Pediatric Obesity, 6(5-6):434-441.

Kinge, J. M. and S. Morris. 2017. The Impact of Childhood Obesity on Health and Health Service Use. Health Services Research, DOI: 10.1111/1475-6773.12708

Kline, B. and J. L. Tobias. 2008. The Wages of BMI: Bayesian Analysis of a Skewed TreatmentResponse Model with Nonparametric Endogeneity. Journal of Applied Econometrics, 23(6):767-793.

Lee, L. F. and J. H. Sepanski. 1995. Estimation of Linear and Nonlinear Errors-In-Variables Models using Validation Data. Journal of the American Statistical Association, 9(429):130-140.

Locke, Adam E., Bratati Kahali, Sonja I. Berndt, et al. 2015. "Genetic Studies of Body Mass Index Yield New Insights for Obesity Biology.” Nature 518: 197-206.

Lundahl, A., K. M. Kidwell, and T. D. Nelson. 2014. Parental Underestimates of Child Weight: A MetaAnalysis. Pediatrics. 133(3):e689-703

Maes, H. H. M., M. C. Neale, and L. J. Eaves. 1997. Genetic and Environmental Factors in Relative Body Weight and Human Adiposity. Behavior Genetics, 27(4):325-351.

Manning, W. G. and J. Mullahy. 2001. Estimating Log Models: to Transform or not to Transform? Journal of Health Economics, (20):461-494.

Monheit, A. C., J. P. Vistnes, and J. A. Rogowski. 2009. Overweight in Adolescents: Implications for Health Expenditures. Economics \& Human Biology, 7(1):55-63.

Nan, C., B. Guo, C. Warner, et al. 2012. "Heritability of body mass index in pre-adolescence, young Adulthood and late adulthood." Eur J Epidemiol. 27: 247-253.

NIH. 1998. NHLBI Obesity Education Initiative Expert Panel on the Identification, Evaluation, and Treatment of Obesity in Adults (US). Clinical Guidelines on the Identification, Evaluation, and Treatment of Overweight and Obesity in Adults: The Evidence Report. Bethesda (MD): National Heart, Lung, and Blood Institute.

O'Connor, D. P. and J. J. Gugenheim. 2011. Comparison of Measured and Parents' Reported Height and Weight in Children and Adolescents. Obesity, 19(5):1040-1046. 
Ogden, C. L., M. D. Carroll, H.G. Lawman, C.D. Fryar, D. Kruszon-Moran, B. K. Kit, and K. M. Flegal. 2016. Trends in Obesity Prevalence Among Children and Adolescents in the United States, 1988-1994 Through 2013-2014. Journal of the American Medical Association, 315(21):2292-2299.

Ogden, C. L., K. M. Flegal, M. D. Carroll, and C. L. Johnson. 2002. Prevalence and Trends in Overweight among US Children and Adolescents, 1999-2000. Journal of the American Medical Association, 288(14):1728-1732.

O'Neill, D. and O. Sweetman. 2013. The Consequences of Measurement Error when Estimating the Impact of Obesity on Income. IZA Journal of Labor Economics, 2(1):3.

O'Neill, D. (2015). Measuring Obesity in the Absence of a Gold Standard. Economics \& Human Biology, 17(0):116-128.

Pelone, F., M. L. Specchia, M. A. Veneziano, S. Capizzi, S. Bucci, A. Mancuso, W. Ricciardi, and A. G. de Belvis. 2012. Economic Impact of Childhood Obesity on Health Systems: a Systematic Review. Obesity Reviews, 13(5):431-440.

Price, R. A. and I. I. Gottesman. 1991. Body Fat in Identical Twins Reared Apart: Roles for Genes and Environment. Behavior Genetics, 21(1):1-7.

Reed, D. and R. A. Price. 1998. Estimates of the Heights and Weights of Family Members: Accuracy of Informant Reports. International Journal of Obesity, 22:827-835.

Shiely, F., K. Hayes, I. J. Perry, and C. C. Kelleher. 2013. Height and Weight Bias: The Influence of Time. PLOS ONE, 8(1):e54386.

Silventoinen, K., B. Rokholm, J. Kaprio, TIA Sorensen. 2010. "The genetic and environmental influences on childhood obesity: a systematic review of twin and adoption studies." International Journal of Obesity, 34: $29-40$.

Small, D. S. and P. R. Rosenbaum. 2008. War and Wages: The Strength of Instrumental Variables and their Sensitivity to Unobserved Biases. Journal of the American Statistical Association, 103(483):924933.

Smith, G. D., J. A. Sterne, A. Fraser, P. Tynelius, D. A. Lawlor, and F. Rasmussen. 2009. The Association between BMI and Mortality using Offspring BMI as an Indicator of Own BMI: Large Intergenerational Mortality Study. British Medical Journal, 339:b5043.

Speliotes, Elizabeth K., Cristen J. Willer, Sonja I. Berndt, et al. 2010. "Association Analyses of 249,796 Individuals Reveal 18 New Loci Associated with Body Mass Index.” Nature Genetics 42: 937-948.

Stock, J. H., J. H. Wright, and M. Yogo. 2002. A survey of Weak Instruments and Weak Identification in Generalized Method of Moments. Journal of Business \& Economic Statistics, 20(4):518-529.

Stunkard, A. J., T. I. Sørensen, C. Hanis, T. W. Teasdale, R. Chakraborty, W. J. Schull, and F. Schulsinger. 1986. An Adoption Study of Human Obesity. New England Journal of Medicine, 314(4):193-198.

Sørensen, T. I. and A. J. Stunkard. 1993. Does Obesity Run in Families Because of Genes? An Adoption Study using Silhouettes as a Measure of Obesity. Acta Psychiatrica Scandanavia, 370(Suppl):67-72. 
Trasande, L. 2010. How Much Should we Invest in Preventing Childhood Obesity? Health Affairs, 29(3):372-378.

Trasande, L. and S. Chatterjee. 2009. The Impact of Obesity on Health Service Utilization and Costs in Childhood. Obesity, 17(9):1749-1754.

Trasande, L. and B. Elbel. 2012. The Economic Burden Placed on Healthcare Systems by Childhood Obesity. Expert Review of Pharmacoeconomics \& Outcomes Research, 12(1):39-45.

Trasande, L., Y. Liu, G. Fryer, and M. Weitzman. 2009. Effects of Childhood Obesity on Hospital Care and Costs, 1999-2005. Health Affairs, 28(4):751-760.

Trogdon, J. G., J. Nonnemaker, and J. Pais. 2008. Peer Effects in Adolescent Overweight. Journal of Health Economics, 27(5):1388-1399.

U.S. Department of Health and Human Services, 2010. The Surgeon General's Vision for a Healthy and Fit Nation. U.S. Department of Health and Human Services, Office of the Surgeon General, Rockville, MD.

Villanueva, E. V. (2001). The Validity of Self-Reported Weight in US Adults: a Population Based CrossSectional Study. BMC Public Health, 1(11).

Vogler, G. P., T. Sørensen, A. J. Stunkard, M. Srinivasan, and D. Rao. 1995. Influences of Genes and Shared Family Environment on Adult Body Mass Index Assessed in an Adoption Study by a Comprehensive Path Model. International Journal of Obesity and Related Metabolic Disorders, 19(1).

Wang, L. Y., Q. Yang, R. Lowry, and H. Wechsler. 2003. Economic Analysis of a School-Based Obesity Prevention Program. Obesity Research, 11(11):1313-1324.

Wardle, J., S. Carnell, C. M. Haworth, and R. Plomin. 2008. Evidence for a Strong Genetic Influence on Childhood Adiposity despite the Force of the Obesogenic Environment. The American Journal of Clinical Nutrition, 87:398-404.

Whitlock, E. P., E. A. O'Connor, S. B. Williams, T. L. Beil, and K. W. Lutz. 2010. Effectiveness of Weight Management Interventions in Children: A Targeted Systematic Review for the USPSTF. Pediatrics, 125(2):e396-e418.

World Health Organization, 2000. Obesity: Preventing and Managing the Global Epidemic. WHO, Geneva, Switzerland. 
Table 1: Descriptive Statistics for Boys

\begin{tabular}{|c|c|c|c|c|}
\hline Variables & Mean & S.D & Min & Max \\
\hline Has positive medical expenditures & 0.75 & 0.43 & 0 & 1 \\
\hline Annual Medical Expenditures* & $\$ 1,441.29$ & $\$ 3,112.23$ & 1.04 & $49,340.88$ \\
\hline BMI (reported) & 22.48 & 4.90 & 6.09 & 75.55 \\
\hline BMI (error-corrected) & 22.62 & 4.48 & 14.57 & 45.63 \\
\hline Obese (reported) & 0.18 & 0.38 & 0 & 1 \\
\hline Obese (error-corrected) & 0.18 & 0.39 & 0 & 1 \\
\hline Severely Obese (reported) & 0.05 & 0.23 & 0 & 1 \\
\hline Severely Obese (error-corrected) & 0.04 & 0.21 & 0 & 1 \\
\hline Hispanic & 0.19 & 0.39 & 0 & 1 \\
\hline Black & 0.19 & 0.39 & 0 & 1 \\
\hline Other race & 0.07 & 0.26 & 0 & 1 \\
\hline Medicaid & 0.26 & 0.44 & 0 & 1 \\
\hline Private Insurance & 0.67 & 0.47 & 0 & 1 \\
\hline Uninsured & 0.08 & 0.26 & 0 & 1 \\
\hline Age in months & 175.02 & 23.76 & 132 & 215 \\
\hline Self-reported & 0.00 & 0.06 & 0 & 1 \\
\hline \multicolumn{5}{|l|}{ Mother } \\
\hline Mother's age under 34 & 0.12 & 0.32 & 0 & 1 \\
\hline Mother's age 35-44 & 0.52 & 0.50 & 0 & 1 \\
\hline Mother's age $45-54$ & 0.34 & 0.47 & 0 & 1 \\
\hline Mother's age 55-64 & 0.03 & 0.17 & 0 & 1 \\
\hline BMI (reported) & 27.77 & 6.51 & 13.72 & 78.30 \\
\hline BMI (error-corrected) & 28.59 & 6.37 & 15.59 & 61.44 \\
\hline HS diploma & 0.29 & 0.45 & 0 & 1 \\
\hline Some college & 0.26 & 0.43 & 0 & 1 \\
\hline Bachelor's degree & 0.17 & 0.38 & 0 & 1 \\
\hline BA plus & 0.10 & 0.29 & 0 & 1 \\
\hline \multicolumn{5}{|l|}{ Father } \\
\hline Has Father in the Sample & 0.66 & 0.47 & 0 & 1 \\
\hline Father's age under 34 & 0.03 & 0.17 & 0 & 1 \\
\hline Father's age $35-44$ & 0.28 & 0.45 & 0 & 1 \\
\hline Father's age 45-54 & 0.30 & 0.46 & 0 & 1 \\
\hline Father's age 55-64 & 0.06 & 0.23 & 0 & 1 \\
\hline BMI (reported) & 19.30 & 13.53 & 14.24 & 65.83 \\
\hline BMI (error-corrected) & 19.46 & 13.63 & 14.89 & 54.56 \\
\hline HS diploma & 0.19 & 0.39 & 0 & 1 \\
\hline Some college & 0.14 & 0.35 & 0 & 1 \\
\hline Bachelor's degree & 0.13 & 0.33 & 0 & 1 \\
\hline BA plus & 0.08 & 0.28 & 0 & 1 \\
\hline \multicolumn{5}{|l|}{ Household } \\
\hline People in the household aged $0-5$ & 0.18 & 0.47 & 0 & 6 \\
\hline People in the household aged $6-17$ & 1.99 & 0.99 & 1 & 8 \\
\hline People in the household aged 18-64 & 2.17 & 0.81 & 1 & 8 \\
\hline People in the household aged $65+$ & 0.04 & 0.21 & 0 & 4 \\
\hline Northeast & 0.18 & 0.38 & 0 & 1 \\
\hline Midwest & 0.22 & 0.41 & 0 & 1 \\
\hline South & 0.37 & 0.48 & 0 & 1 \\
\hline West & 0.23 & 0.42 & 0 & 1 \\
\hline Urban & 0.83 & 0.37 & 0 & 1 \\
\hline
\end{tabular}

Data: Medical Expenditure Panel Survey (MEPS) 2001-2013. Notes: $N=17,943$ (12,633 have positive expenditures). *Mean annual medical expenditures are computed on the subsample with positive expenditures. All entries are in 2013 U.S. dollars. 
Table 2: Descriptive Statistics for Girls

\begin{tabular}{|c|c|c|c|c|}
\hline Variables & Mean & S.D & Min & Max \\
\hline Has positive medical expenditures & 0.78 & 0.42 & 1 & 1 \\
\hline Annual Medical Expenditures* & $\$ 1,411.01$ & $\$ 3,212.94$ & 1.00 & $49,711.20$ \\
\hline BMI (reported) & 21.87 & 4.88 & 10.83 & 73.17 \\
\hline BMI (error-corrected) & 22.64 & 4.56 & 14.41 & 48.69 \\
\hline Obese (reported) & 0.12 & 0.32 & 0 & 1 \\
\hline Obese (error-corrected) & 0.15 & 0.35 & 0 & 1 \\
\hline Severely Obese (reported) & 0.03 & 0.18 & 0 & 1 \\
\hline Severely Obese (error-corrected) & 0.03 & 0.17 & 0 & 1 \\
\hline Hispanic & 0.18 & 0.39 & 0 & 1 \\
\hline Black & 0.20 & 0.40 & 0 & 1 \\
\hline Other race & 0.07 & 0.26 & 0 & 1 \\
\hline Medicaid & 0.26 & 0.44 & 0 & 1 \\
\hline Private Insurance & 0.66 & 0.48 & 0 & 1 \\
\hline Uninsured & 0.07 & 0.26 & 0 & 1 \\
\hline Age in months & 174.22 & 24.01 & 132 & 215 \\
\hline Self-reported & 0.00 & 0.06 & 0 & 1 \\
\hline \multicolumn{5}{|l|}{ Mother } \\
\hline Mother's age under 34 & 0.12 & 0.33 & 0 & 1 \\
\hline Mother's age 35-44 & 0.52 & 0.50 & 0 & 1 \\
\hline Mother's age $45-54$ & 0.33 & 0.47 & 0 & 1 \\
\hline Mother's age 55-64 & 0.03 & 0.16 & 0 & 1 \\
\hline BMI (reported) & 28.01 & 6.47 & 14.52 & 71.62 \\
\hline BMI (error-corrected) & 28.83 & 6.33 & 15.13 & 61.18 \\
\hline HS diploma & 0.29 & 0.45 & 0 & 1 \\
\hline Some college & 0.26 & 0.44 & 0 & 1 \\
\hline Bachelor's degree & 0.16 & 0.37 & 0 & 1 \\
\hline BA plus & 0.10 & 0.30 & 0 & 1 \\
\hline \multicolumn{5}{|l|}{ Father } \\
\hline Has Father in the Sample & 0.65 & 0.48 & 0 & 1 \\
\hline Father's age under 34 & 0.03 & 0.17 & 0 & 1 \\
\hline Father's age $35-44$ & 0.28 & 0.45 & 0 & 1 \\
\hline Father's age $45-54$ & 0.28 & 0.45 & 0 & 1 \\
\hline Father's age 55-64 & 0.05 & 0.22 & 0 & 1 \\
\hline BMI (reported) & 18.78 & 13.66 & 14.24 & 80.29 \\
\hline BMI (error-corrected) & 18.93 & 13.75 & 14.89 & 64.53 \\
\hline HS diploma & 0.19 & 0.40 & 0 & 1 \\
\hline Some college & 0.14 & 0.34 & 0 & 1 \\
\hline Bachelor's degree & 0.11 & 0.32 & 0 & 1 \\
\hline BA plus & 0.09 & 0.28 & 0 & 1 \\
\hline \multicolumn{5}{|l|}{ Household } \\
\hline People in the household aged $0-5$ & 0.18 & 0.48 & 0 & 4 \\
\hline People in the household aged $6-17$ & 1.99 & 0.99 & 1 & 8 \\
\hline People in the household aged 18-64 & 2.13 & 0.82 & 1 & 8 \\
\hline People in the household aged $65+$ & 0.03 & 0.20 & 0 & 3 \\
\hline Northeast & 0.18 & 0.39 & 0 & 1 \\
\hline Midwest & 0.22 & 0.42 & 0 & 1 \\
\hline South & 0.36 & 0.48 & 0 & 1 \\
\hline West & 0.23 & 0.42 & 0 & 1 \\
\hline Urban & 0.83 & 0.37 & 0 & 1 \\
\hline
\end{tabular}

Data: Medical Expenditure Panel Survey (MEPS) 2001-2013. Notes: $N=18,121$ (13,084 have positive expenditures). *Mean annual medical expenditures are computed on the subsample with positive expenditures. All entries are in 2013 U.S. dollars. 
Table 3: Marginal Effects of Youth BMI and Obesity on Annual Medical Expenditures

\begin{tabular}{|c|c|c|c|c|c|c|}
\hline & \multicolumn{3}{|c|}{ Non-IV } & \multicolumn{3}{|c|}{ IV } \\
\hline & BMI & Obesity & $\begin{array}{c}\text { Severe } \\
\text { Obesity }\end{array}$ & BMI & Obesity & $\begin{array}{c}\text { Severe } \\
\text { Obesity }\end{array}$ \\
\hline Boys \& Girls & $26.84 * * *$ & 309.73 *** & $496.09 * * *$ & $103.11 * * *$ & $1354.08 * * *$ & $2627.88^{* * * *}$ \\
\hline $\mathrm{N}=36,064$ & $(3.87)$ & (47.97) & $(81.25)$ & (21.7) & (316.87) & (773.09) \\
\hline Boys & $16.51 * * *$ & $176.82^{* * * *}$ & $283.44 * * *$ & $91.12^{* * * *}$ & $1095.31 * * *$ & $2148.50 * * *$ \\
\hline $\mathrm{N}=17,943$ & (5.01) & (55.39) & (92.09) & (26.59) & (344.4) & $(822.77)$ \\
\hline Girls & $38.58 * * *$ & $484.98 * * *$ & $778.24 * * *$ & $116.81 * * *$ & $1687.3 * * *$ & 3256.42 *** \\
\hline $\mathrm{N}=18,121$ & $(5.32)$ & (73.97) & $(129.66)$ & (27.82) & (455.9) & $(1,130.73)$ \\
\hline
\end{tabular}

Table 4: Predicted Per Capita Total Expenditures from IV Two-Part Model

\begin{tabular}{|c|c|c|c|c|c|}
\hline & $\begin{array}{l}\text { Healthy } \\
\text { Weight }\end{array}$ & Obese & $\begin{array}{c}\text { Average ratio of } \\
\text { col. } 2 \text { to col. } 1\end{array}$ & $\begin{array}{c}\text { Severely } \\
\text { Obese }\end{array}$ & $\begin{array}{c}\text { Average ratio of } \\
\text { col. } 4 \text { to col. } 1\end{array}$ \\
\hline Boys \& Girls & 875.82 & $2,229.90$ & 2.59 & $3,503.70$ & 4.10 \\
\hline $\mathrm{N}=36,064$ & (36.9) & $(289.73)$ & $(.42)$ & $(745.13)$ & (1.01) \\
\hline Boys & 883.85 & $1,979.16$ & 2.28 & $3,032.35$ & 3.52 \\
\hline $\mathrm{N}=17,943$ & (43.92) & $(312.8)$ & $(.46)$ & $(790.01)$ & (1.07) \\
\hline Girls & 863.44 & $2,550.74$ & 3.00 & $4,119.86$ & 4.89 \\
\hline $\mathrm{N}=18,121$ & (46.41) & $(424.21)$ & $(.62)$ & $(1,098.58)$ & (1.49) \\
\hline
\end{tabular}

Data: Medical Expenditure Panel Survey (MEPS) 2001-2013. Notes: BRR standard errors in parentheses. All entries are in 2013 U.S. dollars.

Table 5: Marginal Effects of Youth BMI and Obesity on Annual Medical Expenditures by Source of Payment from IV Two-Part Model

\begin{tabular}{|c|c|c|c|c|c|c|}
\hline & \multicolumn{3}{|c|}{ Third-Party Payer } & \multicolumn{3}{|c|}{ Out-of-Pocket } \\
\hline & BMI & Obesity & $\begin{array}{l}\text { Severe } \\
\text { Obesity }\end{array}$ & BMI & Obesity & $\begin{array}{c}\text { Severe } \\
\text { Obesity }\end{array}$ \\
\hline Boys \& Girls & $99.18 * * *$ & $1312.36^{* * * *}$ & $2641.50 * * *$ & 3.81 & 43.25 & 67.85 \\
\hline $\mathrm{N}=36,064$ & $(20.78)$ & (296.31) & $(776.21)$ & $(3.33)$ & $(40.63)$ & $(67.86)$ \\
\hline Boys & $92.33 * * *$ & $1118.14 * * *$ & $2316.18^{* *}$ & 4.74 & 52.18 & 86.02 \\
\hline $\mathrm{N}=17,943$ & $(27.66)$ & $(347.51)$ & (908.53) & $(4.03)$ & $(47.19)$ & $(83.64)$ \\
\hline Girls & $109.02 * * *$ & $1582.92 * * *$ & $3133.35 * * *$ & 5.07 & 61.49 & 95.09 \\
\hline $\mathrm{N}=18,121$ & $(26.23)$ & (418.08) & $(1,090.51)$ & $(4.07)$ & $(54.93)$ & (92.1) \\
\hline
\end{tabular}


Table 6: Marginal Effects of Child BMI on Annual Medical Expenditures Paid by Insurance among Children with Insurance from IV Two-Part Model

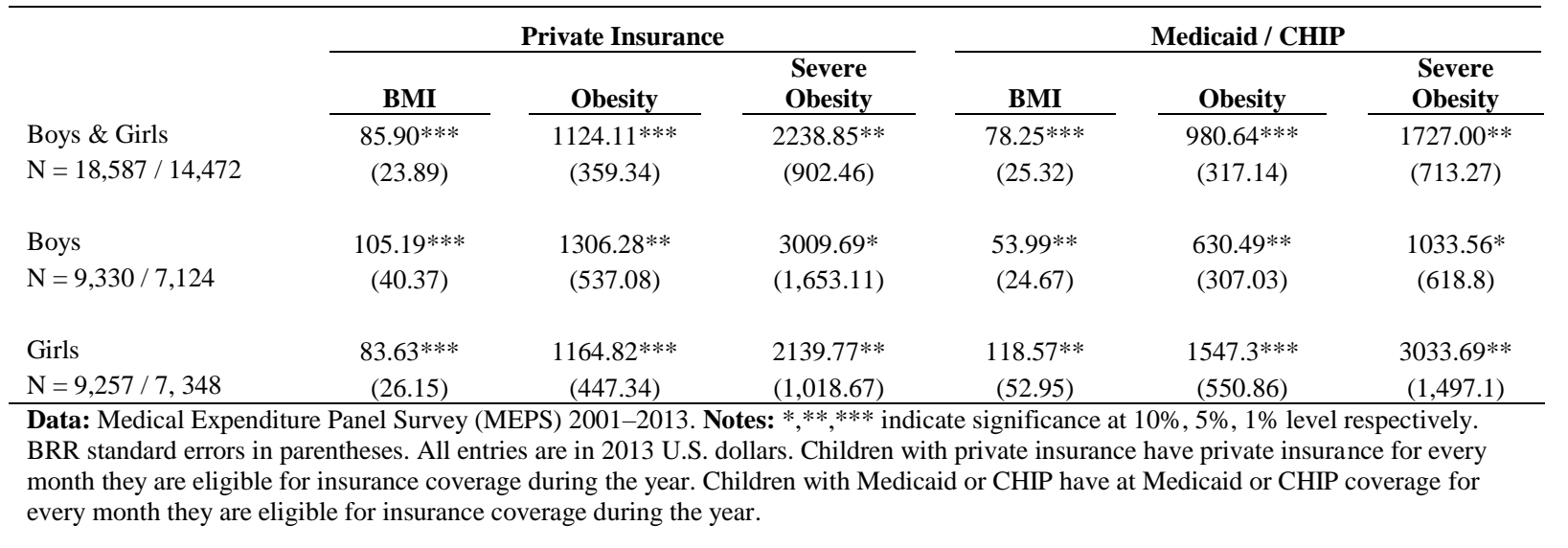

Table 7: Predicted Per Capita Expenditures Paid by Insurance among Enrolled Children from IV Two-Part Model

\begin{tabular}{|c|c|c|c|c|c|}
\hline & $\begin{array}{l}\text { Healthy } \\
\text { Weight }\end{array}$ & Obese & $\begin{array}{c}\text { Average ratio of } \\
\text { col. } 2 \text { to col. } 1\end{array}$ & $\begin{array}{c}\text { Severely } \\
\text { Obese }\end{array}$ & $\begin{array}{c}\text { Average ratio of } \\
\text { col. } 4 \text { to col. } 1\end{array}$ \\
\hline & \multicolumn{5}{|c|}{ Private Insurance } \\
\hline Boys \& Girls & 741.43 & $1,865.55$ & 2.53 & $2,980.28$ & 4.05 \\
\hline $\mathrm{N}=18,587$ & $(42.07)$ & $(332.05)$ & $(.55)$ & (874.09) & $(1.36)$ \\
\hline Boys & 708.85 & $2,015.14$ & 2.85 & $3,718.54$ & 5.25 \\
\hline $\mathrm{N}=9,330$ & (49.64) & $(501.86)$ & $(.88)$ & $(1,617.05)$ & $(2.62)$ \\
\hline Girls & 748.52 & $1,913.34$ & 2.58 & $2,888.29$ & 3.92 \\
\hline \multirow[t]{2}{*}{$\mathrm{N}=9,257$} & $(50.83)$ & $(418.19)$ & $(.68)$ & (988.33) & $(1.54)$ \\
\hline & \multicolumn{5}{|c|}{ Medicaid / CHIP } \\
\hline Boys \& Girls & 585.34 & $1,565.98$ & 2.76 & $2,312.34$ & 4.10 \\
\hline $\mathrm{N}=14,472$ & $(51.54)$ & $(276.64)$ & $(.72)$ & $(671.5)$ & $(1.56)$ \\
\hline Boys & 661.29 & $1,291.78$ & 2.03 & $1,694.85$ & 2.71 \\
\hline $\mathrm{N}=7,124$ & $(77.2)$ & $(252.05)$ & $(.61)$ & $(561.07)$ & $(1.21)$ \\
\hline Girls & 496.71 & $2,044.00$ & 4.19 & $3,530.40$ & 7.25 \\
\hline $\mathrm{N}=7,348$ & $(55.59)$ & $(506.46)$ & $(1.51)$ & $(1,452.45)$ & $(3.85)$ \\
\hline
\end{tabular}

Data: Medical Expenditure Panel Survey (MEPS) 2001-2013. Notes: BRR standard errors in parentheses. All entries are in 2013

U.S. dollars. Children with private insurance have private insurance for every month they are eligible for insurance coverage during the year. Children with Medicaid or CHIP have at Medicaid or CHIP coverage for every month they are eligible for insurance coverage during the year. 
Table 8: Aggregate Medical Expenditures Associated with Obesity from IV Two-Part Model

\begin{tabular}{|c|c|c|c|c|c|}
\hline \multirow{2}{*}{$\begin{array}{r}\text { Year } \\
2001\end{array}$} & \multicolumn{2}{|c|}{$\begin{array}{c}\text { Total Expenditures (Billions of } \\
\text { U.S. Dollars) }\end{array}$} & \multicolumn{2}{|c|}{$\begin{array}{c}\text { Third Party } \\
\text { Expenditures (Billions of U.S. } \\
\text { Dollars) }\end{array}$} & \multirow{2}{*}{$\begin{array}{c}\begin{array}{c}\text { Population } \\
\text { (millions) }\end{array} \\
22.2\end{array}$} \\
\hline & 8.13 & $(3.28,12.98)$ & 7.77 & $(3.12,12.43)$ & \\
\hline 2002 & 7.75 & $(2.89,12.62)$ & 7.30 & $(2.74,11.85)$ & 22.1 \\
\hline 2003 & 8.44 & $(3.22,13.65)$ & 7.93 & $(3.1,12.76)$ & 22.7 \\
\hline 2004 & 8.82 & $(3.68,13.95)$ & 8.76 & $(3.76,13.75)$ & 23.0 \\
\hline 2005 & 8.48 & $(3.63,13.34)$ & 8.25 & $(3.54,12.95)$ & 22.1 \\
\hline 2006 & 8.77 & $(3.72,13.82)$ & 8.64 & $(3.69,13.6)$ & 23.0 \\
\hline 2007 & 7.73 & $(3.02,12.44)$ & 7.56 & $(2.91,12.21)$ & 22.5 \\
\hline 2008 & 9.56 & $(3.35,15.77)$ & 9.84 & $(3.52,16.15)$ & 21.5 \\
\hline 2009 & 10.47 & $(4.05,16.9)$ & 10.77 & $(4.27,17.28)$ & 21.7 \\
\hline 2010 & 10.42 & $(4.19,16.65)$ & 10.54 & $(4.21,16.86)$ & 21.2 \\
\hline 2011 & 9.62 & $(3.56,15.68)$ & 10.00 & $(3.76,16.25)$ & 21.7 \\
\hline 2012 & 9.78 & $(3.63,15.93)$ & 10.02 & $(3.61,16.43)$ & 22.1 \\
\hline 2013 & 13.37 & $(5.66,21.09)$ & 13.60 & $(5.83,21.37)$ & 22.7 \\
\hline 2001-13 Average & 9.33 & $(3.93,14.74)$ & 9.31 & $(3.97,14.64)$ & 22.2 \\
\hline
\end{tabular}




\section{Figure 1: Predicted Relationship Between z-score of BMI and Annual Medical Expenditures}

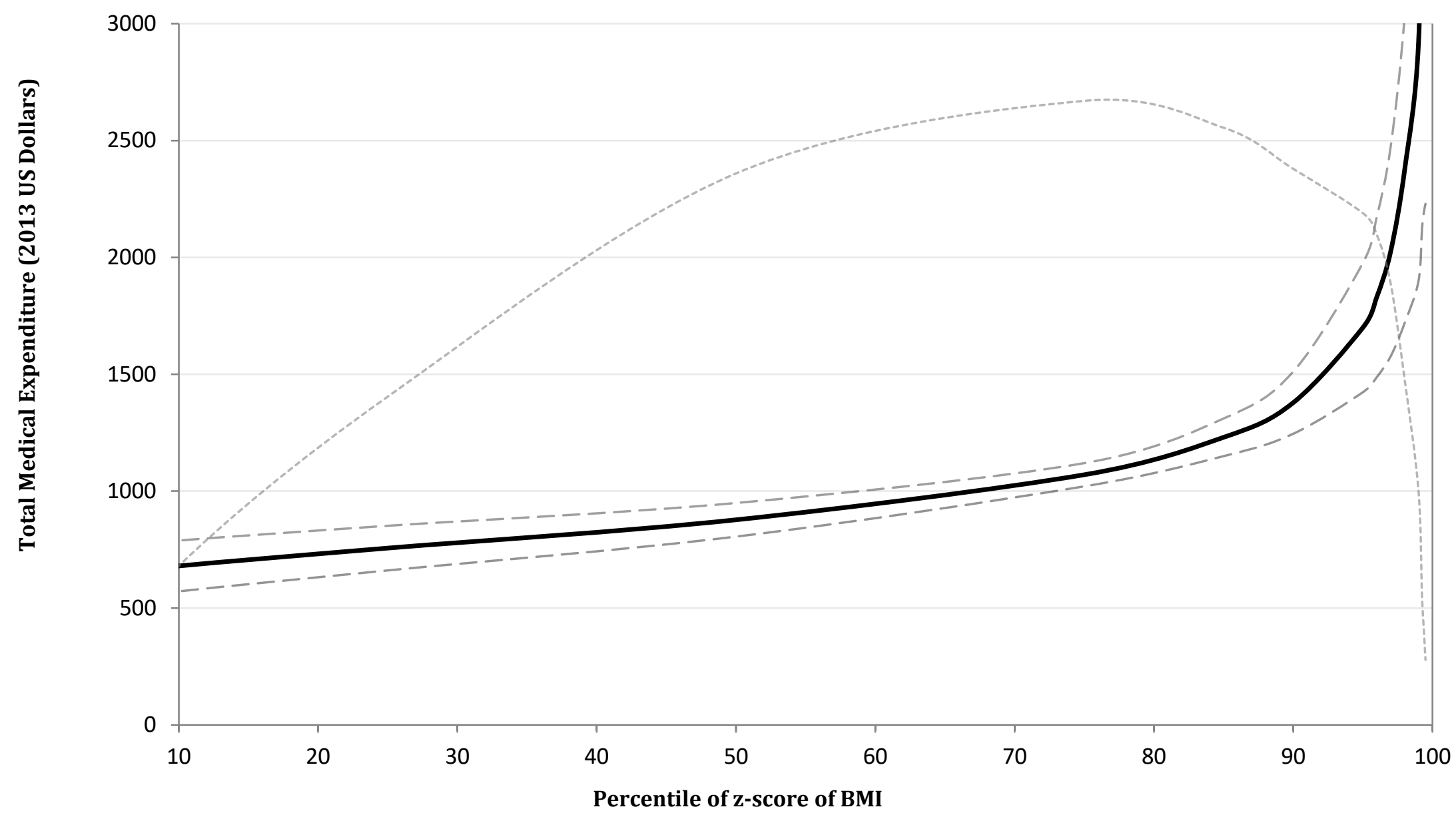

-Boys \& Girls

Data: Medical Expenditure Panel Survey (MEPS) 2001-2013. Notes: Expenditures are in 2013 U.S. dollars. Medical expenditures are denoted by the solid lines and are measured on the left axis. $95 \%$ confidence intervals are indicated by the dashed lines. The distributions of boys and girls in the population are indicated by the dotted line. 
Figure 2: Predicted Relationship Between z-score of BMI and Annual Medical Expenditures by Gender

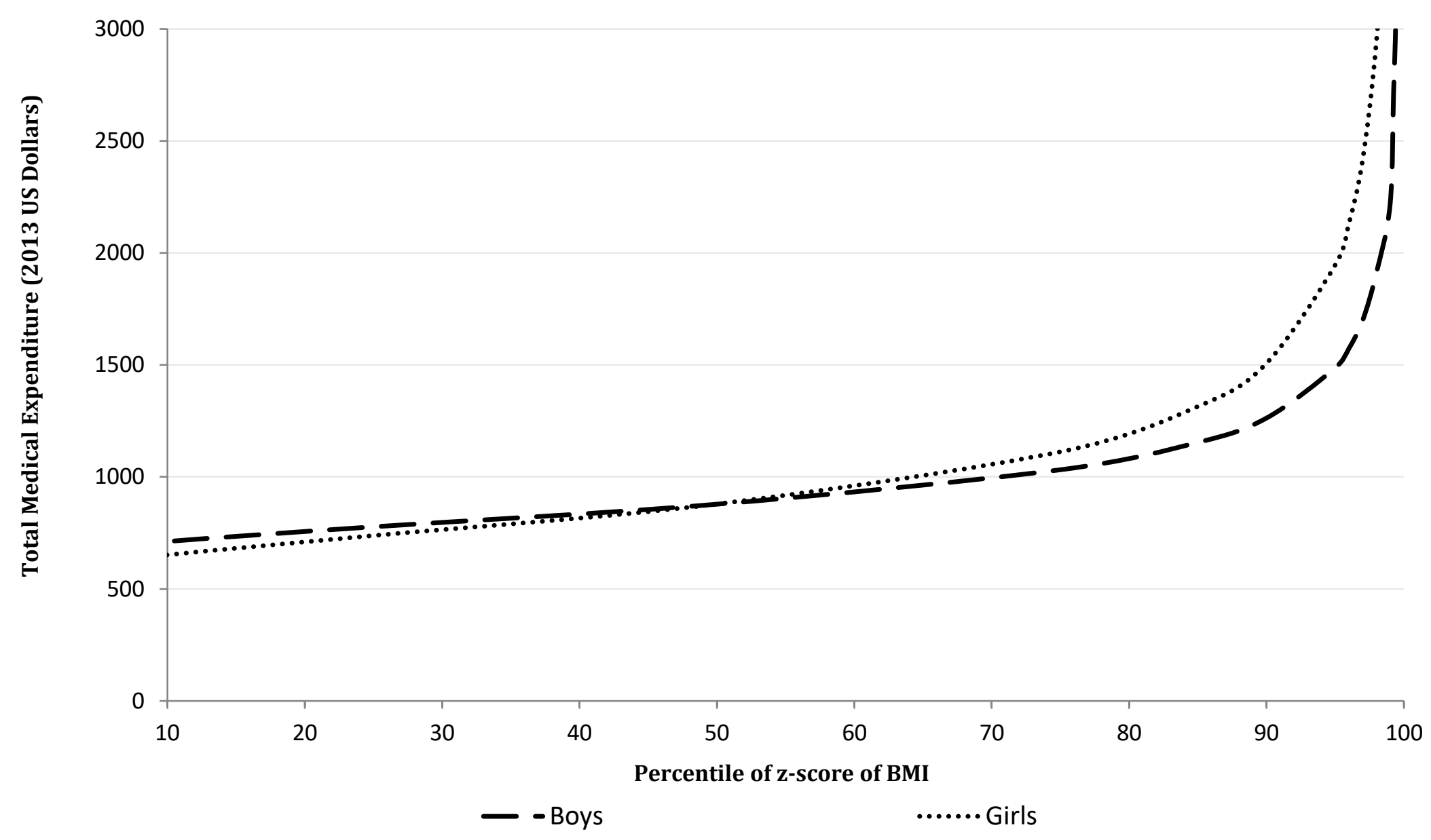

Data: Medical Expenditure Panel Survey (MEPS) 2001-2013. Notes: Expenditures are in 2013 U.S. dollars. 


\section{A Appendix}

\section{A.1 Corrected Body Mass Index}

Error-corrected BMI is computed using the regression calibrated height and weight measures. ${ }^{12}$ We follow the regression calibration method of Courtemanche et al. (2015). A summary of their imputation procedure follows here.

Let $b^{*}$ denote the true measures of height and weight, and $b_{j}$ denote the reported values in sample $j \in\{M, N\}$. In our analysis, the MEPS $(j=M)$ is the principle sample and the NHANES $(j=$ $N$ ) is the validation sample. $\mathrm{RC}$ requires there is a surrogate, or matching agent, present in both the principal and validation samples, as well as the transportability of the surrogate across both datasets. The first condition is that for true values $b^{*}$, there exists a surrogate (typically the reported values) $b_{j}$ such that the distribution of the outcome $y$ given $\left(b^{*}, b_{j}\right)$ is the same as $y$ given $b^{*}$. Essentially the observed heights and weights cannot contain information about the outcome that is not already reflected in true values. Another interpretation is that measurement error cannot be correlated with unobserved variables that influence the outcome. The second condition is transportability of the surrogate; that the underlying distributions of true BMI in both datasets are equal conditional on the surrogate. Transportability implies that,

$$
\mathrm{E}\left(b^{*} \mid b_{M}, Z_{M}\right)=\mathrm{E}\left(b^{*} \mid b_{N}, Z_{N}\right),{ }^{13}
$$

where matrix $Z_{M}$ contains exogenous covariates shared in both datasets (gender, age, race, etc...).

Like Courtemanche et al. (2015), we use the NHANES as a source of validation data. However, we are unable to use proxy-reported height and weight as matching agents for children because the NHANES only includes measured heights and weights for children under the age of 16; Children over the age of 16 may self-report their height and weight. To impute both child and adult height and weight, we follow the method in Courtemanche et al. (2015), and use the percentile rank of height and weight as the matching agent. In this way, misreporting manifests not only as a stochastic process on additive error, but a shift in the height and weight distributions. Using the percentile rank as the matching agent only requires that the expected values of true height and weight conditional on reported measures are monotonically increasing in the reported measures (Courtemanche et al., 2015). For example, Monotonicity implies that individuals who self-report higher weight are expected to have higher true

\footnotetext{
12 MEPS public-use files do not contain height and weight for years after 2000, and are obtained from restricted use files.

${ }^{13}$ This is known as weak transportability (Lee and Sepanski, 1995).
} 
weight than those who self-report lower weight. Courtemanche et al. (2015) test this monotonicity assumption in the NHANES, and do not find evidence to reject it.

For both adults and children, we predict height and weight in the NHANES as a function of gender, race, and their interactions with linear b-splines generated from the percentile rank of height and weight and higher orders of age (age in months for children). We then use the estimated equations to predict true BMI for adults and children in the MEPS. ${ }^{14}$

\section{A.2 Predicted Medical Expenditures}

An alternative approach to characterize the non-linear relationship is to use the method of Cawley and Meyerhoefer (2012) and Cawley et al. (2015b) and predict medical expenditures associated with different levels of BMI by re-estimating our IV 2PM including child BMI and child BMI squared (we instrument using both mothers' BMI and BMI squared). We illustrate the relationship between predicted medical expenditures over the range of BMI for all children (Fig 2) boys (Fig 3) and girls (Fig 4) using the more flexible model of expenditures. Predicted medical expenditures are denoted by the solid line and the distribution of children in the sample is indicated by the dotted line.

For boys and girls pooled, expenditures have a J-shape over BMI, suggesting that medical expenditures rise more sharply for increases in body weight among higher BMI children. The minimum of annual expenditures is near a BMI of 22.5, which is around the threshold for overweight for most children in the sample. Expenditures rise more quickly over BMI > 32.5, which is severely obese for almost all children in the sample. In Figure 3, the expenditures are much flatter. In Figure 4, the J-shape is more pronounced, with higher predicted expenditures over the severely obese range.

\footnotetext{
${ }^{14}$ We use the STATA code provided in Courtemanche et al. (2015) to carry out the regression calibration using
} percentile rank as the surrogate. 


\section{Appendix Figure 1: Predicted Relationship between Boys' and Girls’ BMI and Annual Medical Expenditures}

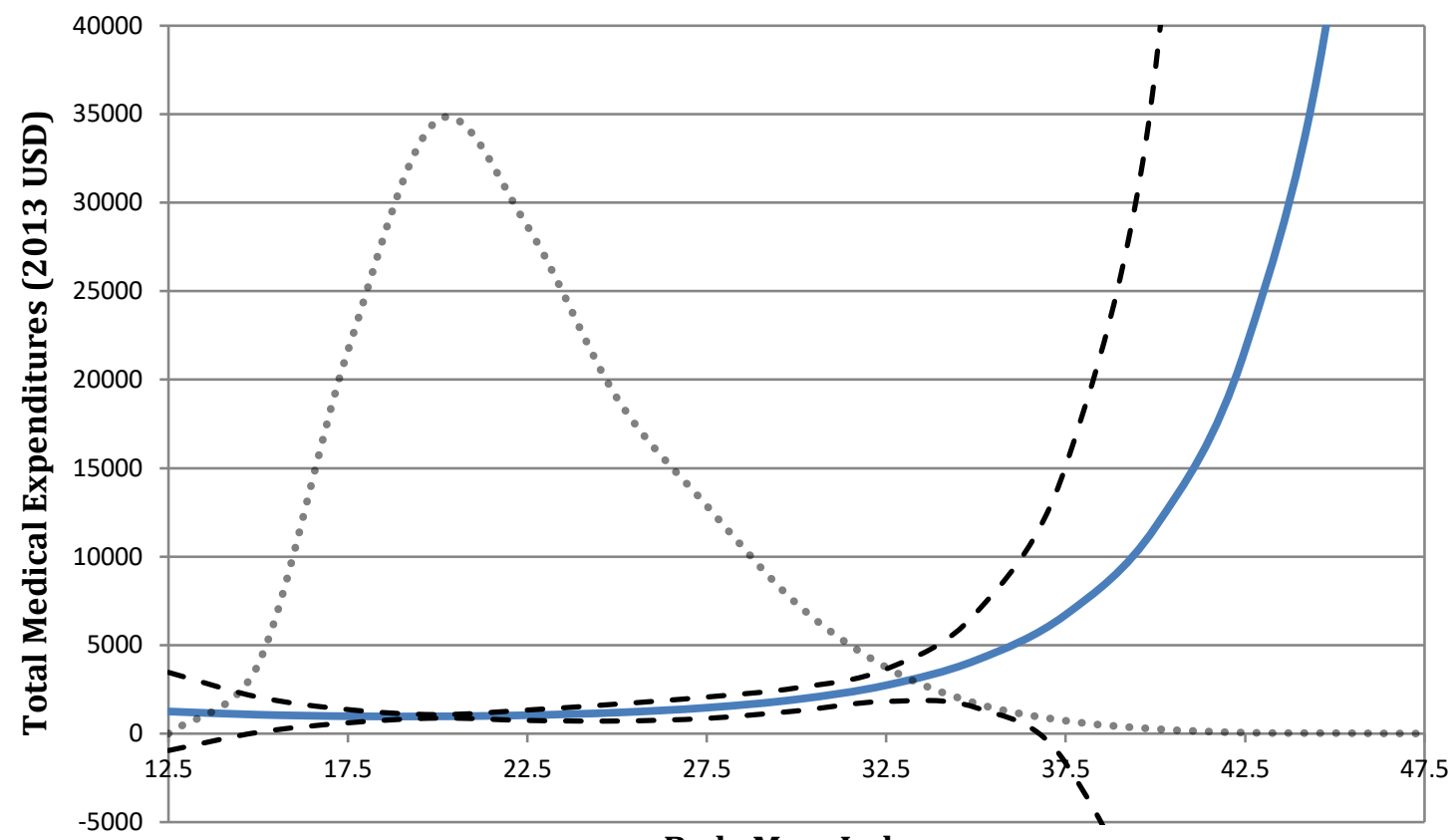

Body Mass Index

Data: Medical Expenditure Panel Survey (MEPS) 2001-2013. Notes: Expenditures are in 2013 U.S. dollars. Medical expenditures are denoted by the solid line and are measured on the left axis. Dashed lines represent $95 \%$ confidence intervals, which have been adjusted for the complex design of the MEPS. The dotted line indicates the distribution of individuals in the population. 


\section{Appendix Figure 2: Predicted Relationship between Boys' BMI and Annual Medical Expenditures}

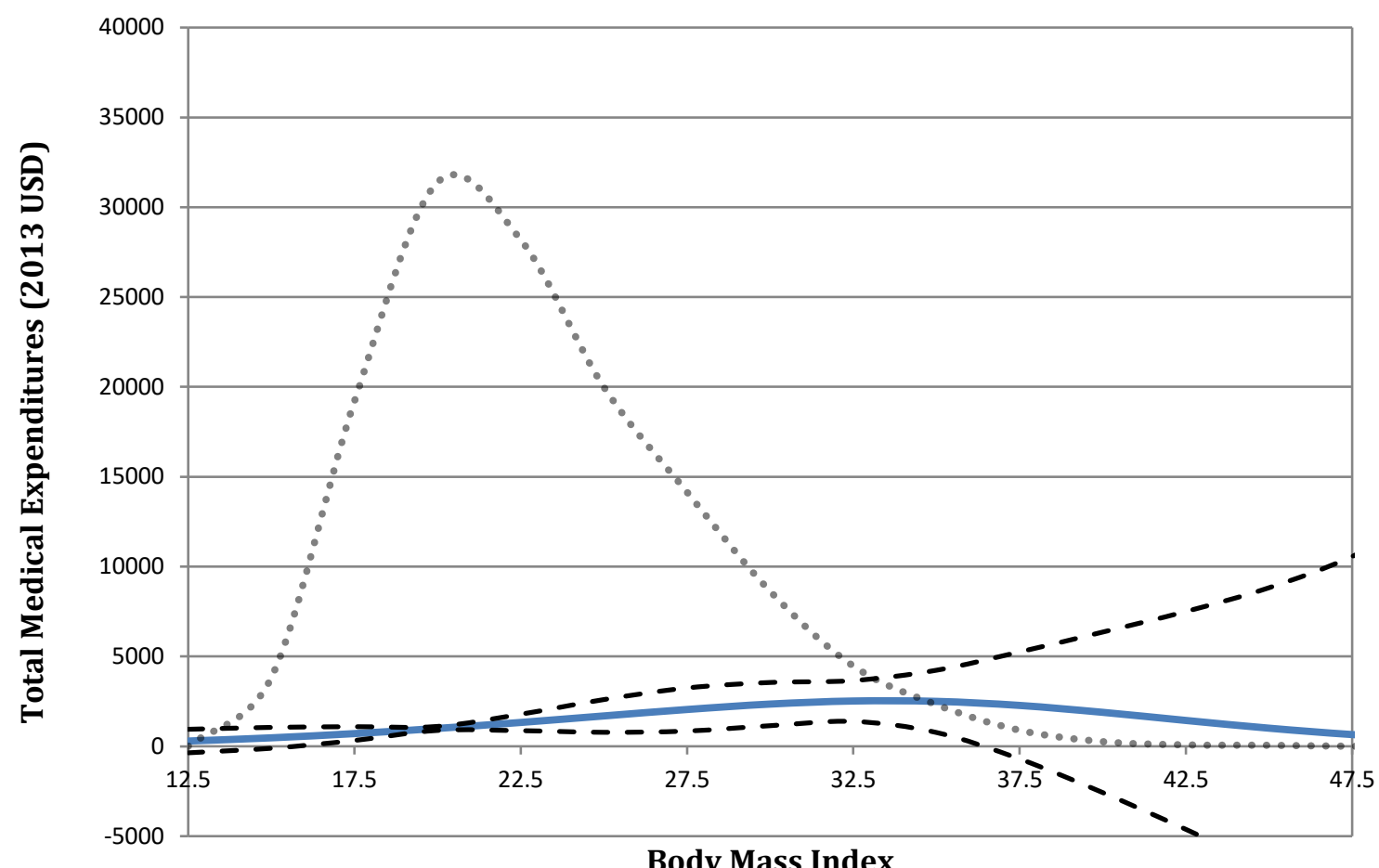

Body Mass Index

Data: Medical Expenditure Panel Survey (MEPS) 2001-2013. Notes: Expenditures are in 2013 U.S. dollars. Medical expenditures are denoted by the solid line and are measured on the left axis. Dashed lines represent $95 \%$ confidence intervals, which have been adjusted for the complex design of the MEPS. The dotted line indicates the distribution of individuals in the population. 
Appendix Figure 3: Predicted Relationship between Girls' BMI and Annual Medical Expenditures

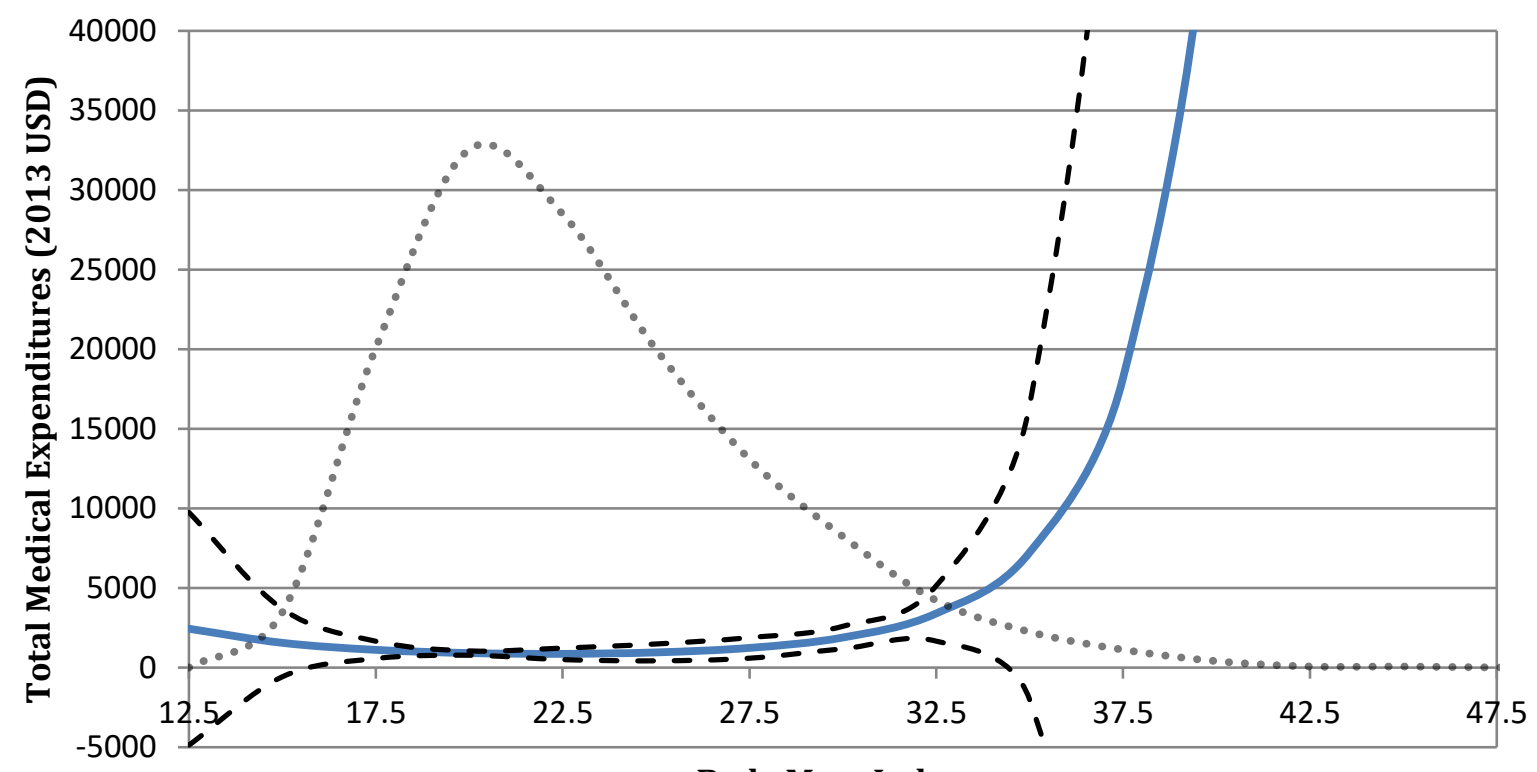

Body Mass Index

Data: Medical Expenditure Panel Survey (MEPS) 2001-2013. Notes: Expenditures are in 2013 U.S. dollars. Medical expenditures are denoted by the solid line and are measured on the left axis. Dashed lines represent $95 \%$ confidence intervals, which have been adjusted for the complex design of the MEPS. The dotted line indicates the distribution of individuals in the population. 